\title{
Severe statin-induced rhabdomyolysis following cholestatic hepatitis induced by amoxicillin-clavulanate
}

$\underline{\text { Rachele Rapetti }}{ }^{\mathrm{a}}$, Elena Merlotti ${ }^{\mathrm{a}}$, Mattia Bellan ${ }^{\mathrm{a}}$, Gian Piero Carnevale Schianca ${ }^{\mathrm{a}}$, Mario Pirisi ${ }^{\mathrm{a}, \mathrm{b}}$

${ }^{\text {a }}$ First Internal Medicine Division, "Maggiore della Carità" University Hospital, Novara, Italy

${ }^{b}$ Department of Clinical and Experimental Medicine, First Internal Medicine Division, University of Eastern Piedmont "A.Avogadro", Novara

\begin{abstract}
:
We report the case of an 86-year-old man with a past history of coronary disease admitted to our internal medicine department for severe asthenia and weakness due to rhabdomyolysis. Three days earlier, he had been discharged from a gastroenterology unit with a diagnosis of amoxicillinclavulanate-induced acute cholestatic hepatitis. A review of his drugs revealed that he had taken atorvastatin $10 \mathrm{mg}$ daily in the previous six years, without clinical or laboratory signs of myopathy. Atorvastatin was therefore stopped, with gradual improvement of the rhabdomyolysis. All concomitant drug therapy needs to be reassessed in elderly patients, especially when they become acutely ill.
\end{abstract}

Keywords: Statin myopathy, rhabdomyolysis, statin toxicity

Received: 02/03/2014

Accepted: $28 / 04 / 2014$

Published: $26 / 05 / 2014$

How to cite this article: Rapetti R, Merlotti E, Bellan M, Carnevale Schianca GP, Pirisi M. Severe statin-induced habdomyolysis following cholestatic hepatitis induced by amoxicillin-clavulanate, EJCRIM 2014;1:doi: 10.12890/2014_000065

Conflicts of Interests: The authors declare that they have no conflicts of interest in this research.

\section{Introduction}

Statin myopathy is a common concern for clinicians managing patients with dyslipidaemia. Well-known risk factors for statin toxicity include advanced age, female gender, hypothyroidism, diabetes, excessive alcohol consumption, concomitant use of drugs that increase statin blood concentration, a history of muscle complaints or elevated creatine kinase and history of renal or hepatic dysfunction ${ }^{1}$. However, the risk of statin toxicity may be easily overlooked when liver 
dysfunction occurs de novo in patients until then tolerant to statins, as exemplified by the present case report.

\section{Case description}

An 86-year-old man with a past history of coronary disease (coronary artery bypass grafting and percutaneous transluminal coronary angioplasty, 6 and 4 years earlier, respectively) was admitted to our internal medicine department for severe asthenia and weakness following a lipothymic event. Three days earlier, he had been discharged from a gastroenterology unit with a diagnosis of amoxicillin-clavulanate-induced acute cholestatic hepatitis. He had been able to ride his bicycle until the day before his first hospitalization, but now he had become unable to get up and walk without help. At physical examination, he appeared an acutely ill elderly man, with jaundice, severe muscle weakness and brown urine. Routine laboratory tests showed that - in comparison to those obtained at discharge - cholestasis indexes had improved, but cytonecrosis indexes and kidney function tests had deteriorated, with clear evidence of rhabdomyolysis (Table 1).

\begin{tabular}{|c|c|c|c|c|c|c|c|c|}
\hline & \multicolumn{2}{|c|}{ First hospital stay } & \multicolumn{6}{|c|}{ Readmission } \\
\hline & Day 1 & $\begin{array}{l}\text { Day } 4 \\
\text { (discharge) }\end{array}$ & Day 1 & Day 4 & Day 5 & Day 8 & $\begin{array}{l}\text { Day } \\
14\end{array}$ & $\begin{array}{l}\text { Day } 22 \\
\text { (discharge) }\end{array}$ \\
\hline $\begin{array}{l}\text { Creatinine } \\
(\mathrm{mg} / \mathrm{dl})\end{array}$ & & 1.44 & 2.09 & 1.45 & 2.19 & 3.02 & 1.72 & 1.59 \\
\hline Bilirubin & & & & & & & & \\
\hline $\begin{array}{l}(\mathrm{mg} / \mathrm{dl}, \\
\text { total) }\end{array}$ & 14.7 & 13 & 10.7 & 6.10 & & 4.7 & 3.6 & 2.7 \\
\hline Direct & 14.3 & & 10.8 & 6.40 & & & & 2.7 \\
\hline AST (U/I) & 229 & 236 & 564 & 1,093 & & & 227 & 95 \\
\hline $\operatorname{ALT}(U / I)$ & 154 & 138 & 188 & 338 & & & 244 & 119 \\
\hline GGT (U/I) & 375 & 336 & 376 & 279 & & & 342 & 442 \\
\hline $\operatorname{ALP}(U / I)$ & 3,486 & & 3,209 & 2,320 & & & & 1307 \\
\hline CPK (U/I) & & & 16,839 & 28,949 & 21,669 & 15,754 & 1,167 & 323 \\
\hline $\begin{array}{l}\text { Myoglobin } \\
\text { (U/I) }\end{array}$ & & & $>10,000$ & $>10,000$ & $>10,000$ & $>10,000$ & 731 & 405 \\
\hline
\end{tabular}

AST, aspartate aminotransferase; ALT, alanine aminotransferase; GGT, gamma-glutamyl transpeptidase; ALP, alkaline phosphatase; CPK, creatine phosphokinase

Table 1: Laboratory tests

The patient had no history of recent crush injuries, immobilization, seizure, extreme exertion, 
hyperkinetic states, alcoholism, electrolyte abnormalities or hypothyroidism. He had been prescribed amoxicillin-clavulanate ( $1 \mathrm{~g}$ twice daily for 7 days) by his general practitioner for lymphoedema, although two months earlier he had had malaise, not better specified, after having received the same drug for bronchitis. A review of his drug therapy revealed that he had consumed atorvastatin $10 \mathrm{mg}$ daily in the previous six years, without any clinical or laboratory signs of myopathy. Atorvastatin was therefore promptly stopped, with gradual improvement first of laboratory indexes and later of clinical conditions. After a hospital stay of approximately 3 weeks, he was able to eat completely independently, to seat himself and to walk short distances with assistance.

\section{Discussion}

Statins are remarkably safe and effective in preventing cardiovascular complications and death and have become the most prescribed class of drugs worldwide. Clinical trials suggest that muscle injury is uncommon with statin therapy alone, with estimated frequencies of $2-11 \%$ for myalgias, $0.5 \%$ for myositis and $<0.1 \%$ for rhabdomyolysis. However, clinical trials, based on patients selected for being at low risk for drug-related complications, may underestimate the true prevalence of statin myopathy in clinical practice ${ }^{2}$. Moreover, the onset of muscle symptoms is usually within weeks to months after the initiation of statin therapy, but may occur any time during treatment ${ }^{3}$. Clinicians should pay particular attention to patients' vulnerability to acute or chronic renal failure, obstructive liver disease and when statins extensively metabolized by cytochrome P-450 3A4 (lovastatin, simvastatin, atorvastatin) are administered together with drugs that interfere with CYP3A44.

Amoxicillin-clavulanate liver injury tends to occur more often in elderly male patients and is almost always associated with comorbidities and/or polytherapy concomitant medications with known potential for hepatic adverse effects ${ }^{5}$.

In this case, it was certainly predictable, because drug therapy needs to be frequently and carefully reassessed in elderly patients, especially when they become acutely ill.

In turn, if statin treatment is not interrupted despite the presence of acute severe cholestasis, rhabdomyolysis is not unexpected.

In our opinion, the two factors that led to this potentially very risky situation were (a) the false confidence created by this gentleman tolerating atorvastatin well over the years and (b) the lack of attention paid by subspecialists to the complexities of drug therapy in elderly patients who present with multiple conditions.

The use of statins in the very elderly is still a matter of debate. The Heart Protection Study, the PROSPER study and the SAGE study illustrate the benefit of statin treatment on coronary or surrogate end points in higher-risk elderly patients, although the data are still somewhat controversial, particularly for individuals $>80$ years of age. Very elderly people are likely to suffer comorbidities, possibly of more immediate importance than future cardiovascular events. In such 
circumstances, prescribing a statin should not be a high priority, particularly when treatment with multiple drugs is ongoing or when adherence is an issue.

In conclusion, this case warns us that physicians should be able to update their practice based on experience and learning and never underestimate the effect of intercurrent events (new diseases, introduction of new drugs), even in patients who have demonstrated good tolerance to statins over the years.

\section{Learning Points}

- The risk of statin myopathy needs to be kept in mind during the course of new diseases or following the administration of new drugs, even when patients have tolerated long-term statins.

- In such circumstances, prescribing a statin should not be a top priority, particularly when treatment with multiple drugs is ongoing or when adherence is an issue.

- Drug therapy needs to be frequently and carefully reassessed in elderly patients, especially when they become acutely ill.

\section{References}

1. 1. Thompson PD, Clarkson P, Karas RH. Statin-associated myopathy, J Am Med Assoc 2003;289:1681-1690.

2. 2. Fernandez G, Spatz ES, Jablecki C, Phillips PS. Statin myopathy: a common dilemma not reflected in clinical trials, Cleve Clin J Med 2011;78:393-403.

3. 3. Tobert JA. Efficacy and long-term adverse effect pattern of lovastatin, Am J Cardiol 1988;62:28J-34J.

4. 4. Rosenson RS.Statins: actions, side effects, and administration, http://www.uptodate.com.

5. 5. Gresser U. Amoxicillin-clavulanic acid therapy may be associated with severe side effects: review of the literature, Eur J Med Res 2001;6:139-149. 